GUILHERME FAVARO CORVO RIBAS

\title{
A PROVA NO PROCESSO ADMINISTRATIVO DE INVESTIGAÇÃO DE CARTEL
}

Tese de Doutorado

Orientadora: Professora Titular Dra. Odete Medauar

UNIVERSIDADE DE SÃO PAULO

FACULDADE DE DIREITO

São Paulo

2015 
GUILHERME FAVARO CORVO RIBAS

\section{A PROVA NO PROCESSO ADMINISTRATIVO DE INVESTIGAÇÃO DE CARTEL}

Tese apresentada à Banca Examinadora do Programa de PósGraduação em Direito, da Faculdade de Direito da Universidade de São Paulo, como exigência parcial para a obtenção do título de Doutor em Direito, na área de concentração de Direito do Estado, sob a orientação da Professora Titular Dra. Odete Medauar.

UNIVERSIDADE DE SÃO PAULO

FACULDADE DE DIREITO

São Paulo 
Autorizo a reprodução e divulgação total ou parcial deste trabalho, por qualquer meio convencional ou eletrônico, para fins de estudo e pesquisa, desde que citada a fonte.

Serviço de Biblioteca e Documentação

Faculdade de Direito da Universidade de São Paulo

\begin{tabular}{|l|}
\hline Ribas, Guilherme Favaro Corvo \\
A prova no processo administrativo de investigação \\
de cartel / Guilherme Favaro Corvo Ribas. -- São Paulo: \\
USP / Faculdade de Direito, 2014. \\
219 f. + Apêndice \\
Orientadora: Profa. Dra. Odete Medauar \\
Tese (Doutorado), Universidade de São Paulo, \\
USP, Programa de Pós-Graduação em Direito, Direito \\
do Estado, 2014. \\
1. Processo administrativo. 2. Cartel. 3. Prova - \\
Processo administrativo. 4. Contraditório. 5. Paridade. \\
I. Medauar, Odete. II. Título.
\end{tabular}


Banca Examinadora 
Para meus pais,

Marina e Clemente. 


\section{AGRADECIMENTOS}

Há muitos a quem agradecer pelo apoio durante a elaboração da presente tese.

Em primeiro lugar, agradeço à minha família. A minha esposa, Roberta, pela inspiração e parceria. A meus filhos, José Luiz, Fernando e Otávio, pela paciência e respeito. A meus pais, Marina e Clemente, e meus sogros, Cleide e Luiz, pelo carinho e suporte.

Em segundo lugar, agradeço aos colegas e amigos que me ajudaram nas diversas etapas da pesquisa: Ana Claudia Beppu, Bruno Drago, Claudio Daolio, Eduardo Pannunzio, Elinor Cotait, Enrico Romanielo, Francisco Lobello, Francisco Sampaio, Helena Lobo, José Carlos Berardo, Larissa Toyamoto, Lucilia Pereira, Márcia Franco, Marco Gasparetti, Maria Cecília Andrade, Mariana Villela, Marídia Santos, Marina Coelho, Pedro Pinheiro, Rodrigo Dall'Acqua, Saylon Alves, Tomás Paiva, Tulio Coelho, Vinícius Ribeiro, Victor Rufino e os integrantes do Centro de Estudos de Direito Administrativo, Ambiental e Urbanístico - CEDAU.

Em terceiro lugar, agradeço aos Professores Diogo R. Coutinho e Vitor Rhein Schirato pelas críticas e sugestões feitas no exame de qualificação.

Por fim, em especial, agradeço à Professora Titular Odete Medauar, não apenas pela firme e eficiente orientação, mas por desafiar-me, desde os tempos da graduação, a refletir sobre o direito administrativo de modo crítico e propositivo. 
RIBAS, Guilherme Favaro Corvo. A prova no processo administrativo de investigação de cartel. 2015. 219 f. Tese (Doutorado). Faculdade de Direito da Universidade de São Paulo, São Paulo, 2015.

\section{RESUMO}

A presente tese de doutorado tem por objetivo demonstrar que a atividade probatória conduzida pelo Conselho Administrativo de Defesa Econômica - CADE, nos processos administrativos de investigação de cartéis, apresenta deficiências e demanda aperfeiçoamento. Para comprovação da tese, foi revisada a jurisprudência do órgão em um período de 15 anos (1999-2014), identificando-se as características e os procedimentos relacionados a essa que é a mais importante etapa dos processos sancionadores: a reconstrução histórica dos fatos controversos. No primeiro capítulo, são examinados o poder de polícia do CADE, suas formas de manifestação, a infração de cartel, a estrutura da autoridade, os tipos de processo, as penalidades e os poderes de investigação. No segundo capítulo, a abordagem recai sobre o objeto, os meios, os modos de obtenção e os momentos da prova. No terceiro capítulo, são identificados os fatores que causam deficiências à atividade probatória à luz do contraditório e da paridade de armas, princípios que devem nortear o exercício da função administrativa. Com base nesse diagnóstico, as notas conclusivas apresentam propostas de aprimoramento da atuação do CADE no campo probatório, que podem contribuir para a tomada de decisões mais céleres, robustas e legítimas.

Palavras-chave: Processo administrativo; cartel; prova; atividade probatória; contraditório; paridade de armas. 
RIBAS, Guilherme Favaro Corvo. Evidence in the cartel investigation administrative process. 2015. 219 p. PhD Thesis, Faculty of Law, University of São Paulo, São Paulo, 2015.

\begin{abstract}
This doctoral thesis aims at demonstrating that the evidentiary activity conducted by the Administrative Council for Economic Defense - CADE, in cartel investigation administrative proceedings, presents deficiencies and requires improvement. For this purpose, CADE's case law for the past 15 years (1999-2014) has been reviewed to identify the characteristics and proceedings related to this stage of the sanctioning process, which is the most important one: the historical reconstruction of the disputed facts. In the first chapter, the following items are discussed: CADE's police power and how it is exercised, cartel violations, authority structure, types of proceedings, penalties, and powers of investigation. In the second chapter, the focus is on the evidence object and phases, means of evidence and means of gathering evidence. In the third chapter, the factors that cause deficiencies to the evidentiary activity are reviewed in light of the adversarial and equality of arms principles that must guide the fulfillment of the administrative function. Based on this diagnosis, the conclusions present proposals to improve CADE's operations in the evidentiary field, which may contribute to render the decision-making process more expedite, solid, and legitimate.
\end{abstract}

Keywords: Administrative process; cartel; evidence; evidentiary activity; adversarial principle; equality of arms principle. 
RIBAS, Guilherme Favaro Corvo. Le preuve dans la procédure administrative d'enquête sur la formation de cartels. 2015. 219 p. Thèse (Doctorat). Faculté de Droit de l'Université de São Paulo, 2015.

\section{RÉSUMÉ}

Cette thèse de doctorat a pour objectif de prouver que l'activité probatoire menée par le Conseil Administratif pour la Défense Économique, le CADE, dans le cadre des procédures administratives d'enquête sur la formation de cartels, présente des défaillances et doit être perfectionnée. Pour démontrer cette thèse, nous analysons la jurisprudence du conseil sur une période de 15 ans (1999-2014), en identifiant les caractéristiques et les processus liés à celle-ci, et qui constituent l'étape la plus importante des procédures de sanction : la reconstitution historique des évènements controversés. Dans le premier chapitre, nous examinons le pouvoir de police du CADE, ses formes de manifestation, l'infraction de formation de cartel, la structure de l'autorité, les types de procédures, les pénalités et les pouvoirs d'investigation. Au cours du deuxième chapitre, nous nous intéressons au but, aux moyens, aux modes d'obtention et aux moments de l'examen. À travers le troisième chapitre, nous identifions les facteurs qui handicapent l'activité probatoire à la lumière de l'analyse contradictoire et de l'égalité des armes, principes qui doivent guider l'exercice de la fonction administrative. À partir de cette analyse, les notes de conclusion présentent des propositions d'amélioration des performances du CADE dans le domaine probatoire, qui peuvent contribuer à la prise de décisions plus rapides, solides et légitimes.

Mots-clés: Procédure administrative, formation de cartel, examen, activité probatoire, procédure contradictoire, égalité des armes . 


\section{SUMÁRIO}

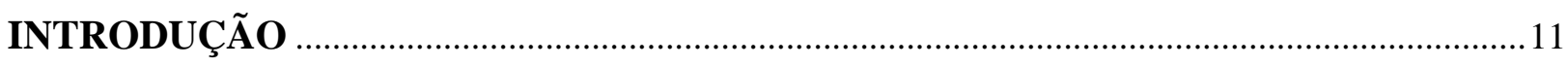

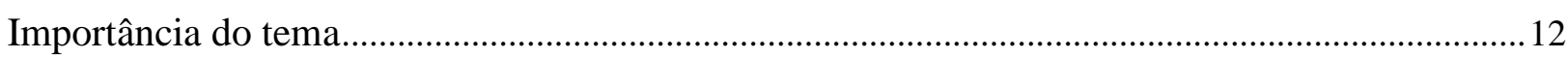

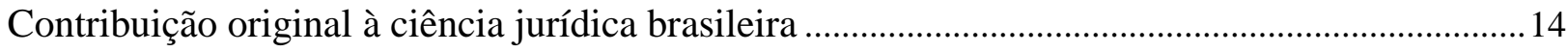

Estrutura

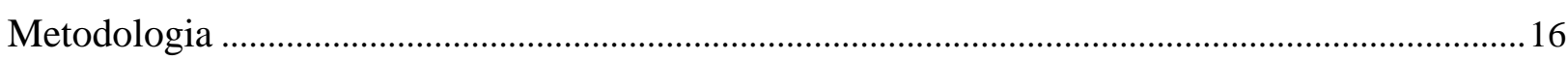

Terminologia

CAPÍTULO 1. ASPECTOS GERAIS DAS INVESTIGAÇÕES DE CARTEL ………..........19

1.1. O poder de polícia do CADE.....................................................................................

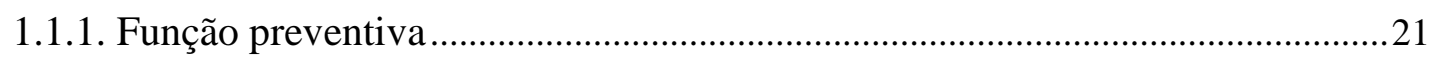

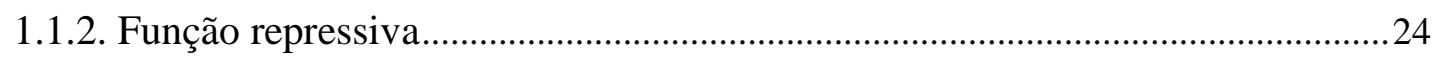

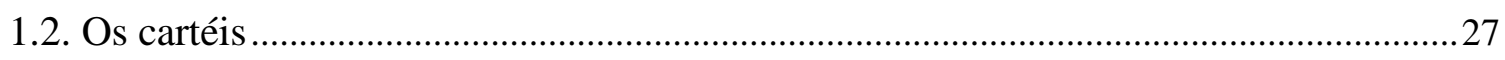

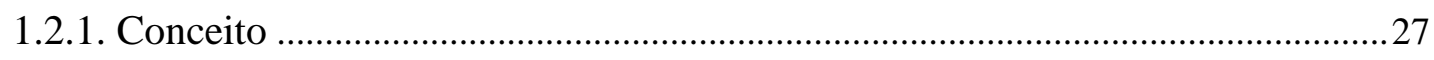

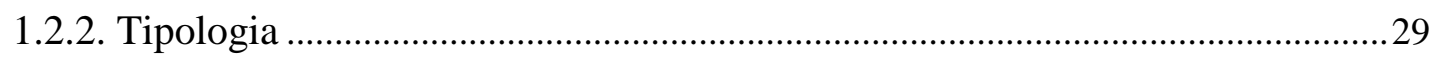

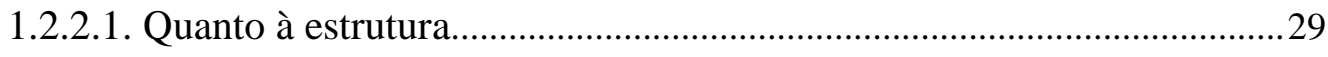

1.2.2.2. Quanto à forma de manifestação …………………………………….......30

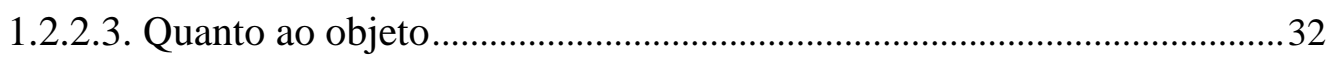

1.2.3. Ambientes propícios para sua formação ………………………………………....33

1.2.4. Justificativas da repressão ………………………………………………........

1.2.5. Caracterização como infração à ordem econômica ................................................35

1.2.5.1. Participação de concorrentes..................................................................

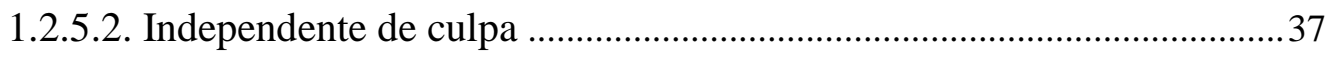

1.2.5.3. Independente de forma........................................................................ 38

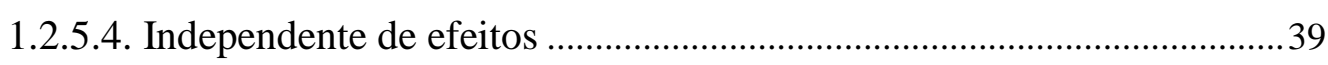

1.2.5.5. Conduta por objeto ou potencialidade de geração de efeitos..................40

1.2.5.5.1. Conduta por objeto ................................................................ 40

1.2.5.5.2. Conduta por potencialidade de geração de efeitos ...................41

1.2.5.6. Aptidão para produção de efeitos anticompetitivos.................................42

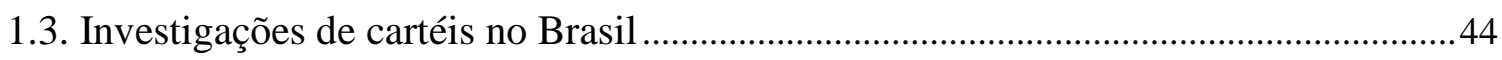

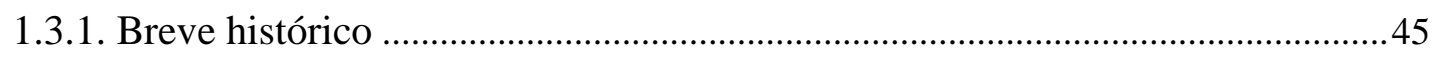

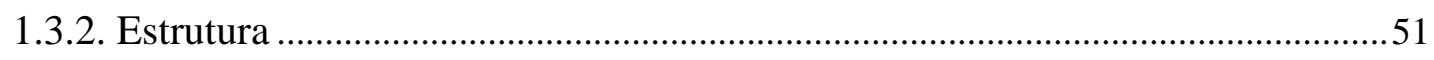

1.3.2.1. Tribunal Administrativo de Defesa Econômica ......................................51

1.3.2.2. Superintendência-Geral ......................................................................

1.3.2.3. Procuradoria Federal Especializada ........................................................53

1.3.2.4. Departamento de Estudos Econômicos .......................................................53 


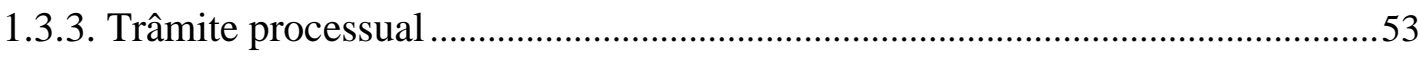

1.3.3.1. Procedimento preparatório de inquérito administrativo ..........................56

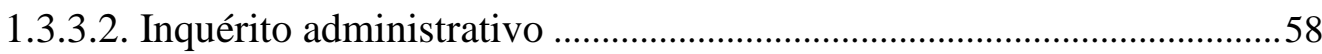

1.3.3.3. Processo administrativo para imposição de sanções administrativas por infrações à ordem econômica.................................60

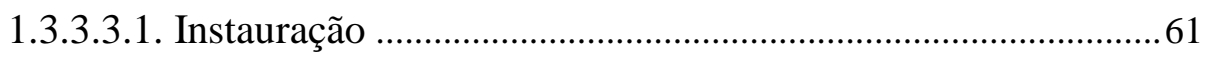

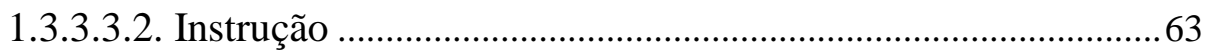

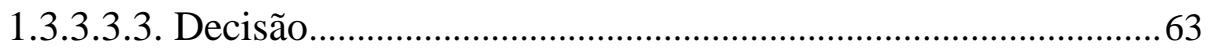

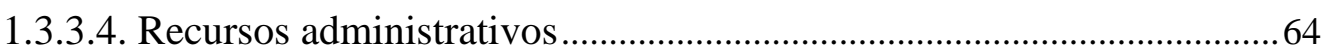

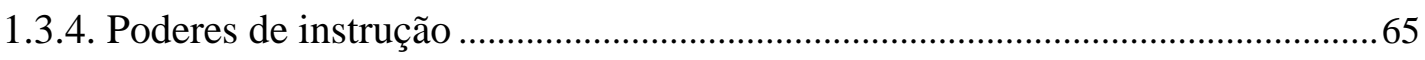

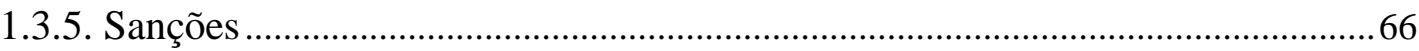

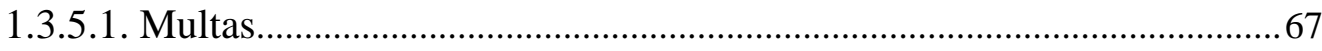

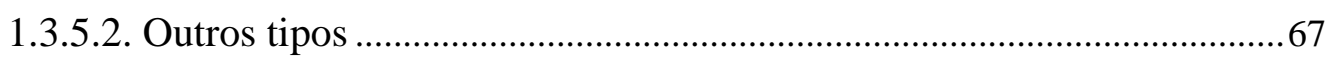

CAPÍTULO 2. PROVA E INVESTIGAÇÃO DE CARTEL .....................................................69

2.1. Preliminarmente: o sistema de provas da lei antitruste ...............................................69

2.2. Noções gerais sobre a prova: conceitos, finalidades e terminologia..............................71

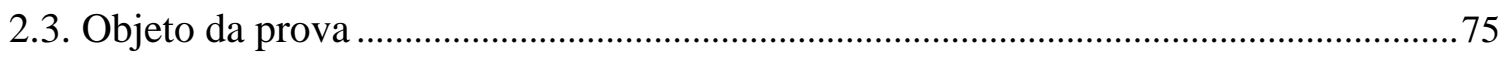

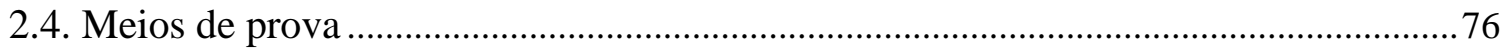

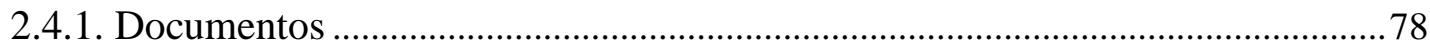

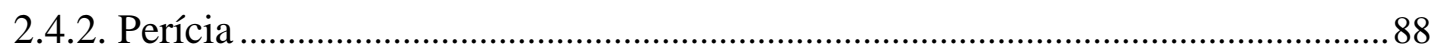

2.4.3. Interrogatório (depoimento pessoal) .............................................................. 91

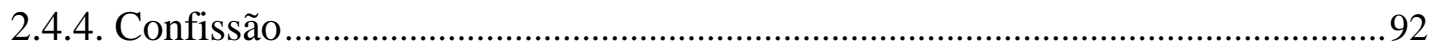

2.4.5. Acordo de leniência (delação premiada)............................................................. 93

2.4.6. Compromisso de cessação de prática .................................................................99

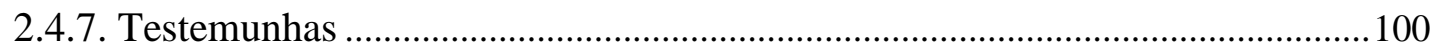

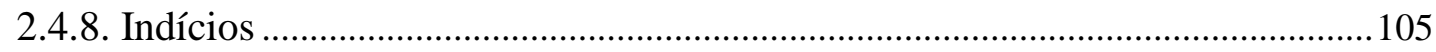

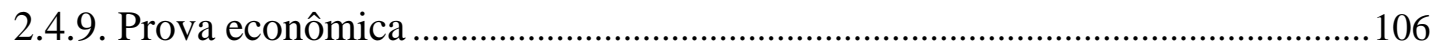

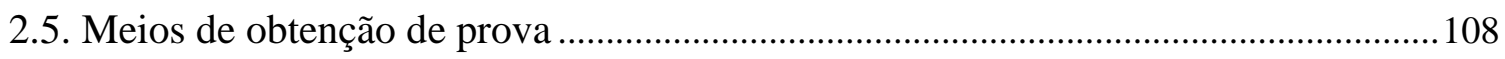

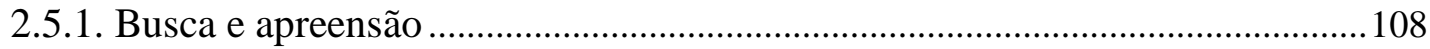

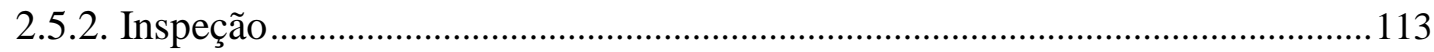

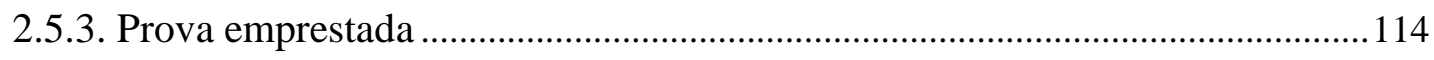

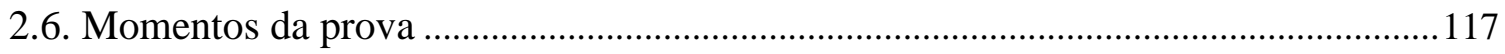

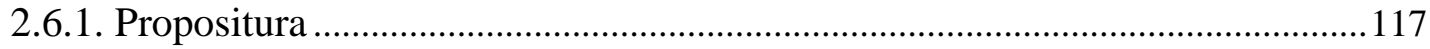

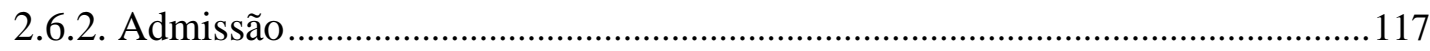

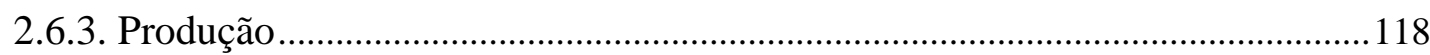

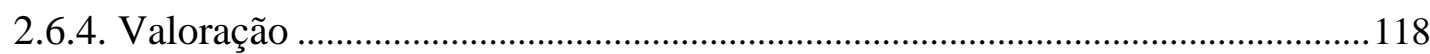


2.6.4.1. Sistema da prova legal .....................................................................118

2.6.4.2. Sistema da íntima convicção................................................................. 120

2.6.4.3. Sistema da persuasão racional ou do livre convencimento motivado.

2.7. Ônus da prova

\section{CAPÍTULO 3. DEFICIÊNCIAS DA ATIVIDADE PROBATÓRIA EM INVESTIGAÇÕES DE CARTEL}

3.1. Deficiências causadas pelo distanciamento do julgador da atividade probatória antes da fase de valoração

3.1.1. Nota preliminar: a alegação de inconstitucionalidade da configuração institucional da autoridade administrativa

3.1.2. Inexistência de fiscalização imediata dos atos da Superintendência-Geral e insuficiência da fiscalização diferida.

3.1.3. Comprometimento da atividade de valoração

3.2. Deficiências causadas pela multiplicidade de funções exercidas pelo acusador.

3.3. Deficiências causadas pela proximidade física e institucional entre o acusador e o julgador

3.4. Deficiências causadas pelo desequilíbrio da paridade de armas em razão da atuação da Procuradoria do CADE e do Ministério Público Federal.

3.5. Deficiências causadas pela preponderância da atuação do CADE em controle de estruturas (função preventiva).

3.6. Deficiências causadas pela delicada relação das funções do Tribunal do CADE de "juiz" e de formulador da política de concorrência.

3.7. Deficiências causadas pela incipiente fiscalização das decisões do CADE pelo Poder Judiciário

3.8. Resumo das deficiências 


\section{INTRODUÇÃO}

O presente estudo tem por objetivo verificar como a atividade probatória é realizada nos processos administrativos de investigação de cartéis, conduzidos pelo Conselho Administrativo de Defesa Econômica - CADE, de modo a identificar suas características e deficiências.

Existente desde 1962, o CADE somente começou a ser percebido pela comunidade empresarial no final da década de 1990, sobretudo na área de controle de estruturas (atos de concentração).

No combate a cartéis, contudo, a evolução ocorreu de maneira mais lenta. O primeiro passo foi dado em 1999, ano da condenação do chamado "cartel do aço", feito até então inédito na história da autarquia. Desde então, mais esforços e recursos vêm sendo empregados para detectar e punir essa prática, considerada o câncer das economias, em razão dos inúmeros prejuízos causados a fornecedores, consumidores e Administração Pública.

Além do desenvolvimento de técnicas de investigação mais sofisticadas e do estreitamento da relação com autoridades criminais e estrangeiras, a atuação repressiva contra cartéis evoluiu de igual forma na esfera legislativa, despontando uma série de alterações no ordenamento jurídico que procuraram dar mais efetividade à política pública.

A mais recente delas ocorreu com a promulgação da Lei n. 12.529/11, responsável por ampla reforma do arcabouço institucional da defesa da concorrência no Brasil. Embora a disciplina dos processos administrativos de investigação de cartéis não tenha sido modificada de maneira substancial, trata-se de oportuno momento para desenvolver a pesquisa, pois o CADE está e continuará passando por significativas transformações, voltando-se cada vez mais para a persecução de condutas anticompetitivas.

Nesse contexto, propôs-se investigar como se deu a evolução do tema da prova ao longo dos 15 anos que se seguiram à primeira condenação de cartel. Por meio dessa abrangente avaliação, torna-se possível compreender os fatores que geram deficiências na atividade probatória, propondo-se melhorias no sistema legal e institucional a fim de eliminá-las ou, ao menos, mitigá-las. 


\section{Importância do tema}

O tema abordado está inserido na linha de pesquisa e projeto de estudo adotados pelo Departamento de Direito do Estado da Faculdade de Direito da USP, a saber, "Convergência dos sistemas romanístico e anglo-americano no direito administrativo brasileiro - Cidadão, administração pública, participação e meios de controle", na medida em que o processo administrativo é uma das formas pelas quais o poder da Administração Pública é parametrizado e controlado.

A importância da processualidade no direito administrativo vem sendo objeto de crescente pesquisa no Brasil, como relata Odete Medauar em seu "A processualidade no direito administrativo", 1 obra pioneira cuja primeira edição foi lançada poucos anos depois da promulgação da Constituição Federal de 1988 e um ano antes da primeira lei de processo administrativo federal (Lei n. 9.784/99).

Dentro do amplo espectro de temas relacionado à processualidade administrativa, optou-se por centrar o estudo no processo administrativo sancionador conduzido pelo CADE. Trata-se de função pouco explorada pela doutrina, sendo de difícil sistematização em razão da diversidade de matérias tratadas pela Administração Pública, que englobam desde a disciplina de funcionários públicos a infrações cometidas por empresas sujeitas a regras de mercado mobiliário ou a regulação específica, como telecomunicações, energia e transporte.

Outro filtro foi a escolha da prova para nortear a pesquisa, tema dos mais explorados na doutrina dos processos civil e penal, tendo contudo recebido pouca atenção no âmbito dos processos administrativos sancionadores, quase nenhuma na esfera antitruste. ${ }^{2}$ A prova, o "farol da verdade", é o principal ponto do processo, onde acusação e defesa devem travar a batalha para mostrar a verdade de suas alegações acerca dos fatos controversos.

Segundo Antonio Magalhães Gomes Filho, a prova constitui problema amplo, complexo e multidisciplinar. Liga-se à busca do conhecimento verdadeiro pelo homem, constituindo um verdadeiro fenômeno cultural, "vinculado a concepções e paradigmas

\footnotetext{
${ }^{1}$ Odete Medauar em seu A processualidade no direito administrativo. 2. ed. São Paulo: Ed. Revista dos Tribunais, 2008.

${ }^{2} \mathrm{Na}$ Europa, o tema da prova nos processos antitruste é muito debatido, tal como relatado de forma minuciosa por MARQUIS, Mel. Rules that govern rules: evidence, proof and judicial control in competition cases. In: EHLERMANN, Claus-Dieter; MARQUIS, Mel. European competition law 2009: the evaluation of evidence and its judicial review in competition cases. Oxford e Portland: Hart Publishing, 2011. p. Xv-xcii.
} 
estreitamente relacionados às características de uma determinada sociedade". Por essa razão, são encontrados em ordenamentos contemporâneos e no curso da história "sistemas probatórios variados, que têm como base pressupostos ideológicos, culturais e sociológicos que correspondem ao modo de ser de cada grupo social."3

Para tornar a pesquisa possível, optou-se por escolher um tipo de processo administrativo antitruste específico, no qual a questão da prova revela-se mais importante e fascinante: o processo de investigação de cartéis.

Cartéis são acordos entre concorrentes para alterar variáveis concorrenciais (preço, oferta, produção etc.) que deveriam ser definidas pelas empresas de maneira independente, em um ambiente de mercado regido pela livre concorrência. Além de infração administrativa, cartel é crime, tipificado nas Leis n. 8.137/90 (art. $4^{\circ}$ ) e 8.666/93 (art. 90), podendo, ainda, ensejar a reparação de danos na esfera civil, consoante as Leis $n$. 12.529/11 (art. 47) e 7.347/85 (art. $1^{\text {o }, ~ V) . ~}$

A importância do tema pode ser medida por sua atualidade no Brasil e no restante do mundo, onde as multas por formação de cartel crescem de maneira significativa a cada ano. Além disso, no Brasil, a prática vem sendo associada a delitos de corrupção e desvio de dinheiro dos contribuintes em poder do governo, recebendo destaque inédito, cujo impacto na atuação administrativa ainda não pode ser mensurado.

Acrescentam temperos à pouco sistematizada análise desse tipo de processo os acordos de leniência (delação premiada), a possibilidade de suspensão das investigações mediante a celebração de acordos (compromissos de cessação de prática) e o aprimoramento da cooperação entre as autoridades administrativas, criminais (polícias e Ministério Público), de controle e estrangeiras.

Diante desse complexo quadro, revela-se apropriado refletir sobre o desenvolvimento da atividade probatória para dar contornos adequados à atuação administrativa. O tema está ligado à crescente preocupação com a legitimidade e eficácia dos arranjos da Administração Pública para dar respostas à sociedade a respeito de temas por ela tutelados, tais como a promoção de ambiente de mercado guiado pela livre concorrência.

\footnotetext{
${ }^{3}$ GOMES FILHO, Antonio Magalhães. Notas sobre a terminologia da prova (reflexos no processo penal brasileiro). In: YARSHELL, Flávio Luiz; MORAES, Maurício Zanoide de (Org). Estudos em homenagem à Professora Ada Pellegrini Grinover. São Paulo: DPI, 2005. p. 303, nota de rodapé omitida.
} 


\section{Contribuição original à ciência jurídica brasileira}

O tema da prova no processo administrativo sancionador referente a práticas de colusão ainda não foi pesquisado de maneira sistemática e individualizada no Brasil ${ }^{4}$ há todavia estudos esparsos examinando a atividade probatória em contextos e intensidades variados.

Alguns o fazem na perspectiva geral do direito antitruste, tal como Calixto Salomão Filho, ${ }^{5}$ Paula A. Forgioni ${ }^{6}$ e Gustavo Lage Noman. ${ }^{7}$

Outros examinam o tema sob a ótica do direito administrativo sancionador, sendo exemplos André Marques Gilberto ${ }^{8}$ e Bruno Corrêa Burini. ${ }^{9}$

Um terceiro grupo dedica-se a examinar os temas de prova na ótica da infração (ou crime) de cartel; dentre os autores, destacam-se Ana Paula Martinez, ${ }^{10}$ Ivo Gico Junior, ${ }^{11}$ Davi de Paiva Costa Tangerino e Pedro Vieira Abramovay. ${ }^{12}$

Por fim, parcela mais numerosa da doutrina vem debruçando-se a determinado momento, meio ou mecanismo de busca de provas, a exemplo de Fernando de Magalhães Furlan, ${ }^{13}$ Fabrício Cobra Arbex ${ }^{14}$ e Renata Rodrigues Praxedes, ${ }^{15}$ dentre outros mencionados ao longo do trabalho.

No entanto, não se identificou, na doutrina pátria, ter sido o tema da prova em investigações de cartel isolado e tratado, sobretudo na perspectiva da finalidade desse tipo de processo, do objetivo da prova e do arranjo institucional da autoridade administrativa.

${ }^{4}$ Por outro lado, vem crescendo a produção doutrinária sobre o processo administrativo em geral, no Brasil e no exterior (vide diversos exemplos em MEDAUAR, Odete. op. cit., p. 154-155).

${ }^{5}$ SALOMÃO FILHO, Calixto. Direito concorrencial: as condutas. São Paulo: Malheiros Ed., 2003.

${ }^{6}$ FORGIONI, Paula A. Os fundamentos do antitruste. 4. ed. São Paulo: Ed. Revista dos Tribunais, 2010.

${ }^{7}$ NOMAN, Gustavo Lage. Das provas em processo concorrencial. 2010. Dissertação (Mestrado) - Faculdade de Direito da Pontifícia Universidade Católica de São Paulo, São Paulo, 2010.

${ }^{8}$ GILBERTO, André Marques. O processo antitruste sancionador: aspectos processuais na repressão das infrações à concorrência no Brasil. São Paulo: Lex, 2010.

${ }^{9}$ BURINI, Bruno Corrêa. Processo administrativo de apuração de conduta anticoncorrencial: perspectiva instrumentalista. 2010. Tese (Doutorado) - Faculdade de Direito, Universidade de São Paulo, São Paulo, 2010.

${ }^{10}$ MARTINEZ, Ana Paula. Repressão a cartéis: interface entre direito administrativo e direito penal. São Paulo: Singular, 2013.

${ }^{11}$ GICO JUNIOR, Ivo. Cartel: teoria unificada da colusão. São Paulo: Lex, 2006.

${ }^{12}$ TANGERINO, Davi de Paiva Costa; ABRAMOVAY, Pedro Vieira et al. Crime de cartel e reparação de danos no poder judiciário brasileiro. Brasília: Ministério da Justiça, 2012. (Série Pensando o Direito, v. 47).

${ }^{13}$ FURLAN, Fernando de Magalhães. Questôes polêmicas em direito antitruste. São Paulo: Lex, 2004.

${ }^{14}$ ARBEX, Fabricio Cobra. Breve análise sobre a busca e apreensão na Lei 8.884/1994, a interpretação conforme a Constituição Federal e o princípio da proibição da prova ilícita. Revista do IBRAC - Direito da Concorrência, Consumo e Comércio Internacional, São Paulo, v. 19, p. 45-66, jan./jun. 2011.

${ }^{15}$ PRAXEDES, Renata Rodrigues. Valoração de prova na condenação de cartéis - o mercado de revenda de combustíveis. Revista do IBRAC - Direito da Concorrência, Consumo e Comércio Internacional, São Paulo, v. 22, p. 341-354, jul./dez. 2012. 
Destarte, esta pesquisa pretende contribuir para a ciência jurídica brasileira de forma inovadora, podendo ser útil para orientar a Administração Pública e demais partes do processo sobre a importância da adequada realização da atividade probatória, bem como servir de convite para as autoridades judiciais (re)avaliarem seu papel de revisão das decisões administrativas. Mais importante, espera-se que as reflexões ora realizadas possam resultar em factíveis propostas de aprimoramento.

\section{Estrutura}

O trabalho encontra-se organizado em três capítulos, além da introdução e das notas conclusivas.

No primeiro capítulo, são apresentadas as principais características da função repressiva em matéria concorrencial e do processo administrativo de investigação de cartéis, com destaque para sua caracterização como infração administrativa, a evolução da política de combate a cartéis no Brasil, a estrutura dos órgãos de defesa da concorrência, os tipos e o trâmite dos processos, os poderes de instrução e as penalidades aplicáveis.

No segundo capítulo, a atividade probatória é dissecada, examinando-se desde a definição do objeto até os meios de prova (documentos, testemunhas, perícias etc.) e de sua obtenção (buscas e apreensões, acordos de leniência, inspeções etc.). Além da análise do sistema de provas aplicável aos processos administrativos conduzidos pelo CADE, são discriminados os momentos da prova, com ênfase no conteúdo da fase de valoração.

No terceiro capítulo, são identificados os fatores que causam deficiências à atividade probatória no âmbito desses processos à luz do contraditório e da paridade de armas, princípios que devem nortear o exercício da função administrativa.

As notas conclusivas trazem sugestões de aprimoramento de modo a eliminar ou mitigar a ocorrência das deficiências detectadas na pesquisa. O principal objetivo das propostas é conferir transparência à atividade probatória e revestir o processo administrativo de imparcialidade e legitimidade.

A todo o momento, os temas abordados são debatidos e relacionados com os dados obtidos na pesquisa jurisprudencial, cuja metodologia encontra-se a seguir explicada. 


\section{Metodologia}

A pesquisa foi concentrada na análise da jurisprudência do CADE a respeito de cartéis. Selecionaram-se dados atinentes a provas, capazes de proporcionar amplo panorama do assunto, útil inclusive para fins de identificação de temas a serem desenvolvidos em novas pesquisas.

Em razão do caráter protagonista da pesquisa empírica neste estudo, necessário discorrer sobre os critérios utilizados.

O primeiro critério foi temporal. O marco inicial é 27 de outubro de 1999, data da primeira condenação de cartel, no âmbito do Processo Administrativo n. 08000.015337/1997-48. O termo final é 26 de outubro de 2014, totalizando um período de 15 anos de atividade do CADE na condução de processos dessa natureza, bastante representativo do ponto de vista científico.

Foram revisadas as atas de 470 das 471 sessões de julgamento realizadas neste período, disponíveis no sítio eletrônico do CADE (a única ata não disponível é a da $22^{\mathrm{a}}$ Sessão Reservada, realizada em 12 de abril de 2000), catalogadas na Tabela 1 do Apêndice.

O segundo critério foi a natureza sancionadora do processo. Em suas sessões de julgamento, o CADE decide diversos tipos de processo administrativo, tendo sido selecionados apenas os de cunho sancionador, cuja decisão pode resultar na aplicação de penalidades; são aqueles listados no art. 48, III, e disciplinados nos arts. 69 a 83, da Lei n. 12.529/11 (equivalentes aos revogados arts. 32 a 51, da Lei n. 8.884/94).

Destarte, foram excluídos os seguintes processos decididos pelo Tribunal: inquérito administrativo para apuração de infrações à ordem econômica (art. 48, II), ${ }^{16}$ processo administrativo para análise de ato de concentração econômica (art. 48, IV), processo administrativo para imposição de sanções processuais incidentais (art. 48, VI), compromisso de cessação (art. 85) e recurso voluntário em medida preventiva (art. 84, § $2^{\circ}$ ). Sob a disciplina da Lei n. 8.884/94, também foram excluídas as averiguações preliminares (revogados arts. 30 e 31 ), equivalentes aos inquéritos administrativos. ${ }^{17}$

\footnotetext{
${ }^{16}$ Os inquéritos administrativos são examinados pelo Tribunal do CADE apenas se houver avocação (art. 67, $\S \S 1^{\circ}$ e $2^{\circ}$ ). No período da pesquisa, não houve casos de avocação.

${ }^{17}$ Ao contrário dos inquéritos administrativos, examinados pelo Tribunal do CADE apenas se avocados, todas as averiguações preliminares eram examinadas e decididas pelo antigo CADE, em sede de recurso de ofício.
} 
O terceiro critério foi relacionado à natureza da conduta investigada. Foram reunidos apenas os processos de investigação de cartéis tipificados no art. 36, §3º, I, da Lei n. 12.529/11, ou no revogado art. 21, I e VIII, da Lei n. 8.884/94, ${ }^{18}$ excluindo-se os de investigação de condutas unilaterais, praticados por apenas um agente, e os demais casos de condutas concertadas que não se enquadram na referida tipificação. ${ }^{19}$

O quinto critério foi a prescrição: conforme dados da Tabela 4 do Apêndice, foram excluídos 23 processos prescritos (21 em razão da incidência de prescrição intercorrente e dois pela prescrição quinquenal). A decisão de eliminar esses casos da base da pesquisa deve-se à inexistência de decisão de mérito e, consequentemente, à incompletude da atividade probatória.

O resultado foi a seleção dos 73 processos administrativos listados na Tabela 5 do Apêndice.

Com relação aos processos judiciais, a pesquisa foi feita a partir de lista fornecida pela Procuradoria do CADE em 2 de abril de 2014, tendo sido identificadas as ações judiciais nas quais foi pleiteada a anulação ou revogação da decisão administrativa. Outras ações incidentais (cautelares, mandados de segurança) ou processos de cobrança movidos pelo CADE (execuções fiscais) não foram objeto de pesquisa.

As questões de prova foram extraídas dos votos dos Conselheiros do CADE, não tendo sido revisadas discussões constantes de peças produzidas pela acusação, pela defesa ou pelos demais órgãos pareceristas. A opção deve-se à obrigação imposta ao julgador de relatar e debater essas questões na fase decisória.

Em paralelo à pesquisa empírica, realizou-se análise teórica, nas doutrinas pátria e estrangeira, em especial a europeia. O recorte teórico concentra-se no processo administrativo sancionador, sobretudo o antitruste. No que tange às questões da prova,

\footnotetext{
${ }^{18}$ Condutas tipificadas em outros incisos podem ter sido igualmente investigadas nos processos selecionados, porém o que importa para a pesquisa é identificar a ocorrência da tipificação nos citados dispositivos legais. Por exemplo, no Processo Administrativo n. 08012.008501/2007-91 (2013), algumas empresas do mercado de telefonia móvel foram investigadas por conduta exclusionária de margin squeeze (Lei n. 8.884/94, art. 21, V), mas também o foram por formação de cartel (Lei n. 8.884/94, art. 21, I), sendo esta a tipificação que se presta aos objetivos do presente trabalho.

${ }^{19} \mathrm{~A}$ lista dos processos excluídos que compõem o segundo grupo aparece nas Tabelas 2 e 3 do Apêndice. Na Tabela 2, são listados os casos de investigação de tabelamento ou sugestão de preços, praticados no âmbito ou com o envolvimento de associações de classe, sindicatos patronais, cooperativas, seus dirigentes ou empregados (alguns deles foram tipificados de forma incorreta nos dispositivos relativos a cartéis). $\mathrm{Na}$ $\underline{\text { Tabela 3 }}$, relacionam-se outros casos excluídos com a correspondente justificativa (e.g., foram excluídos os processos cujo polo passivo era integrado por apenas uma entidade, embora instaurados com base nos dispositivos aplicáveis a investigações de cartel).
} 
também são examinadas a experiência internacional e estudos desenvolvidos nos processos civil e penal, quando pertinentes.

\section{Terminologia}

No presente trabalho, a pessoa contra a qual são imputados os fatos objeto de apuração no processo administrativo de investigação de cartéis é denominada “administrado", "representado" ou "acusado". A despeito de a Lei n. 12.529/11 utilizar o termo "representado", prefere-se o emprego de "acusado", tal como consta no art. 5, LV, da Constituição Federal.

A seu turno, a Superintendência-Geral e a extinta SDE são denominadas “acusador". Seria mais preciso o termo "investigador-acusador-julgador", pois suas funções em matéria de apuração de cartéis vão muito além da mera acusação. Traçando um paralelo com o processo penal, a Superintendência-Geral equivaleria à somatória da polícia e do Ministério Público, acrescida de significativa parcela de poderes detida pelos juízes criminais ao longo da fase investigativa (pré-processual) e processual (nos atos de instauração e instrução probatória).

Por fim, o termo "julgador" é atribuído tanto ao Tribunal do CADE, na qualidade de órgão decisório, como aos Conselheiros, de forma individual. 


\section{NOTAS CONCLUSIVAS}

A tese tem como objetivo realizar uma abrangente análise da atividade probatória nos processos administrativos de investigação de cartéis, de modo a identificar deficiências e propor melhorias. Assim, foram examinadas suas características, peculiaridades e conformidade com o ordenamento jurídico, tomando por base a experiência do CADE em um período de 15 anos, contado a partir da primeira condenação de cartel, em 1999.

Sem dúvida, desde o final da década de 1990, houve uma evolução muito significativa na atuação administrativa voltada à coibição das práticas de cartelização. Dentre os principais propulsores dessa marcha, destacam-se as alterações legislativas que introduziram mecanismos de obtenção de provas mais sofisticados, a efetiva utilização destas ferramentas e a criação de canais de diálogo e cooperação com autoridades de controle, criminais e estrangeiras.

No entanto, ao lado desses avanços, o estudo identificou significativas deficiências decorrentes do arranjo institucional, do acúmulo de funções da autoridade, de algumas regras processuais assimétricas e da ausência de controles efetivos sobre a atuação administrativa. Essas deficiências demandam mudanças para equilibrar a paridade de armas entre a Administração e os administrados, de forma a criar-se ambiente propício ao desenvolvimento de efetivo contraditório.

A instalação de verdadeiro contraditório na esfera administrativa, além de obrigatória em razão de mandamento constitucional, é a melhor solução para possibilitar a realização da reconstrução histórica dos fatos sob investigação de maneira mais precisa. Quanto maior for o diálogo e o estímulo ao duelo entre defesa e acusação, mais robustas, céleres e, sobretudo, legítimas serão as decisões.

A apresentação de propostas revela-se bastante oportuna. A reforma de 2011 racionalizou e conferiu maior eficácia ao sistema de controle de estruturas (atos de concentração), abrindo caminho para a alocação de esforços na análise de condutas anticompetitivas. No entanto, ao estabelecer o combate a cartéis como objetivo mediato da reestruturação jurídico-institucional, a reforma pecou pela ausência de reflexão a respeito de seu impacto na condução e decisão dos processos administrativos sancionadores. 
Nesse sentido, um novo passo deve ser dado para aprimorar o sistema administrativo de repressão a cartéis. Para tanto, serão apresentadas propostas com vistas a criar um modelo verdadeiramente acusatório, com alocação adequada dos papéis de defesa, acusação e decisão, em aproximação ao sistema jurisdicional. Para a implementação da primeira (e mais importante) delas, será necessária a reforma parcial da Lei n. 12.529/11. As demais independem de alteração legislativa, podendo ocorrer por meio de mudança dos regulamentos.

A primeira proposta é atribuir competência ao julgador para acompanhar a atividade probatória desde o início, na fase inquisitorial, em substituição ao modelo vigente pelo qual toma contato com a prova apenas na fase de valoração. Responsabilizando-se pela condução do processo administrativo, o julgador será alçado à posição de terceiro imparcial, de modo que defesa e acusação serão instadas, de maneira automática, a assumir posturas mais aguerridas durante a atividade probatória, em benefício da reconstituição histórica dos eventos investigados.

Assim, todos os atos do acusador em matéria probatória deverão ser autorizados pelo julgador, desde a fase inquisitorial (solicitação de busca e apreensão, realização de inspeções, requisições de documentos e informações a terceiros, celebração de acordo de leniência etc.) até o término da fase de instrução. Nesta, será o julgador a examinar os pedidos de provas das partes, conduzir a produção e determinar seu encerramento, podendo, inclusive, exercer os poderes de instrução complementar, de acordo com os contornos propostos neste estudo.

Os Conselheiros deverão possuir graduação em Direito e receber intenso treinamento em técnicas de decisão, o que pode demandar cooperação com as escolas da carreira de magistratura. O Presidente e os seis Conselheiros serão treinados para conduzir a atividade probatória de modo isento e eficiente, devendo sempre almejar e garantir o estímulo ao contraditório e a paridade de armas entre Administração-acusadora e administrado-acusado.

O Tribunal será dividido em três turmas de julgamento, compostas de três membros cada, atuando o Presidente em todas elas. As decisões serão monocráticas até a fase final do processo; a única decisão tomada pela turma, por maioria de votos, será a final, que resultará na condenação ou arquivamento do processo administrativo.

Em termos de procedimento, a Secretaria do Tribunal será informada da instauração de procedimento preparatório ou inquérito administrativo pela Superintendência-Geral, 
devendo um dos seis Conselheiros ser sorteado para acompanhar a investigação, atribuindo-se-lhe os poderes de controle e autorização das medidas de obtenção de provas. Se o acusador encontrar indícios de cartel, deverá preparar a "denúncia” administrativa (com os devidos pedidos de produção de provas), que será encaminhada para um segundo Conselheiro, membro de turma de julgamento distinta, também escolhido por sorteio. Se decidir pela aceitação da "denúncia", este segundo Conselheiro (o Relator) instaurará o processo administrativo e intimará os acusados a apresentar defesa, procedendo, na sequência, à admissão, produção e, por fim, à valoração das provas.

Em segundo lugar, a Procuradoria e o Ministério Público Federal devem deixar de atuar nos processos administrativos na função de fiscal da lei. A primeira, no mínimo, nos casos em que tenha auxiliado a Superintendência-Geral no exercício de seus poderes investigatórios e de instrução. O segundo, no mínimo, naqueles processos em que tenha havido cooperação entre promotores e o CADE durante as fases anteriores ao encaminhamento dos autos para manifestação do Parquet.

A implementação da proposta reduzirá o tempo de tramitação dos feitos e permitirá que ambos a Procuradoria e o Ministério Público dediquem-se com mais ardor às demais tarefas que lhes incumbem no dia a dia da prática de combate a cartéis: a primeira na defesa do CADE em juízo e o segundo no oferecimento de ações civis públicas e criminais.

Em terceiro lugar, propõe-se a adaptação aos quadros brasileiros da figura do Hearing Officer e do procedimento peer review europeu, este último equivalente à prática de criação de times "vermelho" e "azul" da Divisão Antitruste do Departamento de Justiça dos Estados Unidos. Tratar-se-á de mecanismo interno do CADE para promover a avaliação da atividade probatória por equipe ou pessoa distinta daquela responsável pela condução do caso, com vistas a sugerir melhorias no exercício da função administrativa, em especial no tocante a questões envolvendo a atividade probatória e os direitos dos administrados. O exercício da função de "advogado do Diabo" poderá ser desempenhado por uma Coordenação-Geral da Superintendência-Geral ou equipe da Procuradoria não envolvida nas investigações.

A adoção dessa proposta tenderá a diminuir a incidência das predisposições cognitivas características dos processos administrativos de investigação de cartel, na medida em que os servidores envolvidos na investigação serão confrontados com ideias e críticas de terceiros sem envolvimento direto com o objeto da investigação. 
Em quarto lugar, e seguindo o mesmo raciocínio da proposta anterior, sugere-se dividir as Coordenações-Gerais da Superintendência-Geral durante as fases inquisitorial e processual. Antes da instauração, uma delas será responsável pela investigação e preparação da "denúncia" administrativa, a ser aceita ou não pelo Superintendente-Geral (e, posteriormente, pelo julgador). A outra equipe passará a atuar após a instauração do feito, sendo responsável pelas tarefas até o encerramento da instrução probatória. A Procuradoria poderá fazer a mesma divisão, caso tenha auxiliado a Superintendência-Geral durante as investigações e, em momento posterior, venha a ser convocada pelo Conselheiro Relator a atuar como fiscal da lei.

Em quinto lugar, com vistas a aumentar a transparência e fomentar as discussões em plenário a respeito de questões de fato e de mérito, propõe-se vedar discussões entre os Conselheiros referentes ao mérito e à legalidade dos processos administrativos de investigação de cartéis antes das sessões de julgamento do Tribunal. A medida tenderá a resultar em incentivo à melhor preparação dos votos e à requisição de vistas para aprofundamento da análise das alegações e provas da defesa e da acusação.

Em sexto lugar, o Departamento de Estudos Econômicos deverá ser fortalecido para atuar como "perito" nos processos de investigação de cartéis, servindo ao Tribunal, de maneira imparcial, na avaliação de questões econômicas apresentadas pela defesa e pela acusação. Assim, deve-se vedar a influência do Superintendente-Geral na escolha do Economista-Chefe, cabendo-lhe apenas acatar a indicação feita pelo Presidente do Tribunal.

Em sétimo lugar, deverá ser criado Guia de Boas Práticas para a condução da atividade probatória, contendo regras de comportamento e procedimentais a beneficiar o bom e justo andamento dos feitos. Neste manual, deverão ser inseridas normas que fortaleçam e incentivem a formação do contraditório e garantam a igualdade de armas dos acusados e do acusador (e.g., a defesa sempre deverá falar por último após amplo acesso aos elementos colhidos pela acusação, o interrogatório deverá ser instituído como meio de defesa, indicando-se o direito do acusado de permanecer calado etc.).

Esse conjunto de propostas foi idealizado para conferir mais eficiência e legitimidade ao atual sistema administrativo de combate a cartéis. Revestindo-se o desenvolvimento da atividade probatória de robustez, lisura e transparência, o sistema produzirá decisões sólidas e duradouras, mais propensas a dissuadir a prática de cartel e incentivar o fiel cumprimento da lei. 


\section{REFERÊNCIAS}

AGUIAR, Jean Menezes de. Rechaço à judicialização das decisões do CADE. In: ZANOTTA, Pedro; BRANCHER, Paulo (Coords.). Desafios atuais do direito da concorrência. São Paulo: Singular, 2008. p. 191-212.

ALLENDESALAZAR, Rafael; MARTÍNEZ-LAGE, Paloma. Evidence gathered through leniency: from the prisoner's dilema to a race to the bottom. In: EHLERMANN, ClausDieter; MARQUIS, Mel. European competition law 2009: the evaluation of evidence and its judicial review in competition cases. Oxford e Portland: Hart Publishing, 2011. p. 565-578.

ALMUNIA, Joaquin. Some highlights from EU competition enforcement. Disponível em: <http://europa.eu/rapid/press-release_SPEECH-14-608_en.htm>. Acesso em: 21 out. 2014.

ARBEX, Fabricio Cobra. Breve análise sobre a busca e apreensão na Lei 8.884/1994, a interpretação conforme a Constituição Federal e o princípio da proibição da prova ilícita. Revista do IBRAC - Direito da Concorrência, Consumo e Comércio Internacional, São Paulo, v. 19, p. 45-66, jan./jun. 2011.

ARRUDA, Vivian Anne Fraga do Nascimento; CRUZ, Tatiana Lins. A florescência da cooperação internacional em matéria antitruste no Brasil: enfoque à cooperação no combate aos cartéis transnacionais. Revista do IBRAC - Direito da Concorrência, Consumo e Comércio Internacional, São Paulo, v. 20, p. 175-222, jul./dez. 2011.

BADARÓ, Gustavo Henrique Righi Ivahy. Direito processual penal. São Paulo: Elsevier, 2008.t. 1 .

BAEL, Ivo van. Due process in EU competition proceedings. Wolters Kluwer, 2011.

BERRISCH, Georg M. The EU Courts Play a Crucial Role in Ensuring Compliance of the EU's System of Competition Law Enforcement With Due Process Rights, 16.06.2014. Disponível em: <https://www.competitionpolicyinternational.com/the-eu-courts-play-acrucial-role-in-ensuring-compliance-of-the-eu-s-system-of-competition-law-enforcementwith-due-process-rights/>. Acesso em: 01 dez. 2014.

BRASIL. Ministérios da Justiça, Fazenda e Planejamento. Exposição de Motivos n ${ }^{o} 00107-$ A. Disponível em: <http://www.planalto.gov.br/ccivil_03/projetos/EXPMOTIV/EMI/2005/107\%20A\%20\%20MJ\%20MF\%20MP.htm>. Acesso em: 13 out. 2014.

Secretaria de Direito Econômico e Agência Nacional do Petróleo, Gás Natural e Biocombustíveis. A Defesa da Concorrência no Mercado de Combustíveis - ANP/SDE. Disponível em: <http://www.anp.gov.br/?dw=2552>. Acesso em: 05 nov. 2014. 
BRONCKERS, Marco; VALLERY, Anne. Fair and effective competition policy in the EU: which role for authorities and which role for the courts after Menarini?, Ago. 2012. Disponível em: <http://papers.ssrn.com/sol3/papers.cfm?abstract_id=2137524>. Acesso em: 10 dez. 2014.

BURINI, Bruno Corrêa. Processo administrativo de apuração de conduta anticoncorrencial: perspectiva instrumentalista. 2010. Tese (Doutorado) - Faculdade de Direito, Universidade de São Paulo, São Paulo, 2010.

CADE. Balanço do biênio da Lei 12.529/11 e perspectivas da defesa da concorrência no Brasil. em: <http://www.cade.gov.br/upload/Balan\%C3\%A7o\%202\%20anos\%20nova\%20lei.pdf>. Acesso em: 13 out. 2014.

Plano Estratégico 2013-2016. Disponível em: <http://www.cade.gov.br/upload/CADE\%20-\%20Plano\%20Estratégico\%2020132016\%20-\%20versão\%201\%200.pdf>. Acesso em: 13 out. 2014.

Relatório "Iniciativa: novo processo de Análise de Atos de Concentração Econômica”. Disponível em: $<$ http://repositorio.enap.gov.br/bitstream/handle/1/1077/Novo\%20processo\%20de\%20An $\%$ C3\%A1lise \%20de\%20Atos\%20de\%20Concentra\%C3\%A7\%C3\%A3o\%20Econ\%C3\% B4mica.pdf?sequence=1>. Acesso em: 15 out. 2014.

CAOIMH, Aindrias Ó. Standard of proof, standards of review and evaluation of evidence in antitrust and merger cases: perspective of Court of Justice of the European Union. In: EHLERMANN, Claus-Dieter; MARQUIS, Mel (Eds.). European competition law 2009: the evaluation of evidence and its judicial review in competition cases. Oxford e Portland: Hart Publishing, 2011. p. 271-284.

CARVALHO, Vinícius Marques de. Discurso de posse, 18.07.2012. Disponível em: <http://www.cade.gov.br/upload/Discurso \%20de\%20posse\%20do\%20presidente $\% 20 \mathrm{do} \%$ 20Cade\%20(vinicius).pdf >. Acesso em: 09 nov. 2014.

; GODOY, João Paulo. O juízo de conhecimento aplicável à análise de estruturas concorrenciais e a função cognitiva desempenhada pelo direito societário. In: OLIVEIRA, Amanda Flávio de; RUIZ, Ricardo Machado (Orgs.). Remédios antitruste. São Paulo: Singular, 2011. p. 127-143.

; RAGAZZO, Carlos Emmanuel Joppert (Coords.). Defesa da concorrência no Brasil: 50 anos. Brasília: Conselho Administrativo de Defesa Econômica - CADE, 2013. 
CASSAGNE, Juan Carlos. En torno al derecho administrativo sancionador y la aplicabilidad de los principios del derecho penal. In: MEDAUAR, Odete; SCHIRATO, Vitor Rhein (Coords.). Poder de polícia na atualidade. Belo Horizonte: Fórum, 2014. p. 57-77.

CASTILLO DE LA TORRE, Fernando. Evidence, proof and judicial review in cartel cases. In: EHLERMANN, Claus-Dieter; MARQUIS, Mel (Eds.). European competition law 2009: the evaluation of evidence and its judicial review in competition cases. Oxford e Portland: Hart Publishing, 2011. p. 319-406.

CHISHOLM, Alex; CURRIE, David; JARVIS, Tim. Institutional design and decisionmaking in the competition and markets authority, 11.09.2014. Disponível em: <https://www.competitionpolicyinternational.com/institutional-design-and-decisionmaking-in-the-competition-and-markets-authority/> . Acesso em: $01 \mathrm{dez} .2014$.

CINTRA, Antonio Carlos de Araújo; GRINOVER, Ada Pellegrini; DINAMARCO, Cândido Rangel. Teoria geral do processo. 28. ed. São Paulo: Malheiros Ed., 2012.

COMISSÃO EUROPEIA. Best Practices on the conduct of proceedings concerning Articles 101 and 102 TFEU. Disponível em: <http://ec.europa.eu/competition/consultations/2010_best_practices/best_practice_articles. pdf >. Acesso em: 01 set. 2014.

Guidance on procedures of the Hearing Officers in proceedings relating to Articles 101 and 102 TFEU (ex- articles 81 and 82 EC). Disponível em: <http://ec.europa.eu/competition/consultations/2010_best_practices/hearing_officers.pdf>. Acesso em: 01 set. 2014.

CORDOVIL, Leonor. Das infrações da ordem econômica. In: CORDOVIL, Leonor; CARVALHO, Vinícius Marques de; BAGNOLI, Vicente; ANDERS, Eduardo Caminati. Nova lei de defesa da concorrência comentada. São Paulo: Ed. Revista dos Tribunais, 2011.

COSTA, Helena Regina Lobo da. Direito penal econômico e direito administrativo sancionador: ne bis in idem como medida de política sancionadora integrada. 2013. Tese (Livre-docência) - Faculdade de Direito da Universidade de São Paulo, São Paulo, 2013.

DINAMARCO, Cândido Rangel. Fundamentos do processo civil moderno. 6. ed. São Paulo: Malheiros Ed., 2010. t. 1.

. A instrumentalidade do processo. 14. ed. São Paulo: Malheiros Ed., 2009.

EZRACHI, Ariel; KINDL, Jir I'. Cartel seria crime? A longa jornada da aplicação unilateral da lei ao consenso internacional. Revista de Defesa da Concorrência, n. 1, maio p. 149-169, 2013. 
FALECK, Diego. Apresentação política brasileira de defesa da concorrência: combate a cartéis e programa de leniência. In: ENCONTRO NACIONAL DA $3^{\mathrm{a}}$ CÂMARA DE COORDENAÇÃO E REVISÃO DO MPF, 11. 2010. Disponível em: http://3ccr.pgr.mpf.mp.br/secretaria-executiva-1/coordenacao/eventos/vii-encontrodocs/xi-encontro/anexos-1/sde>. Acesso em: 01 dez. 2014.

FARINA, Elizabeth Maria Mercier Querido. Quatro anos à frente do CADE. Revista IBRAC - Direito da Concorrência, Consumo e Comércio Internacional, São Paulo, v. 16 n. 1 , p. 149-168, 2009.

FERRAZ, Sérgio; DALLARI, Adilson Abreu. Processo administrativo. São Paulo: Malheiros Ed., 2000.

FIGUEIREDO JÚNIOR, Gerardo; GUTIERRA, Ricardo A. Limites ao processo investigatório. In: ZANOTTA, Pedro; BRANCHER, Paulo (Org.). Desafios atuais do direito da concorrência. São Paulo: Singular, 2008. p. 257-272.

FORGIONI, Paula A. Os fundamentos do antitruste. 4. ed. São Paulo: Ed. Revista dos Tribunais, 2010.

FORRESTER, Ian. A bush in need of pruning: the luxuriant growth of "light judicial review". In: EHLERMANN, Claus-Dieter; MARQUIS, Mel (Eds.). European competition law 2009: the evaluation of evidence and its judicial review in competition cases. Oxford e Portland: Hart Publishing, 2011. p. 407-452.

FURLAN, Fernando de Magalhães. Questões polêmicas em direito antitruste. São Paulo: Lex, 2004.

GABAN, Eduardo Molan; DOMINGUES, Juliana Oliveira. Direito antitruste: o combate a cartéis. São Paulo: Saraiva, 2009.

GASCÓN ABELLÁN, Marina. Los hechos en el derecho: bases argumentales de la prueba. Madrid: Marcial Pons, 1999.

GICO JUNIOR, Ivo. Cartel: teoria unificada da colusão. São Paulo: Lex, 2006.

GILBERTO, André Marques. O processo antitruste sancionador: aspectos processuais na repressão das infrações à concorrência no Brasil. São Paulo: Lex, 2010.

GLADER, Marcus. Best practices in Article 101 and 102 Proceedings: some suggestions for improved transparency. 16.04.2010. Disponível em: <https://www.competitionpolicyinternational.com/best-practices-in-article-101-and-102proceedings-some-suggestions-for-improved-transparency/>. Acesso em: $01 \mathrm{dez} .2014$. 
GLOBAL COMPETITION REVIEW. Rating enforcement 2014. The Annual Ranking of the World's Top Antitrust Authorities, v. 16, n. 6, Jun. 2014.

GOLDBERG, Daniel Krepel. Poder de compra e política antitruste. São Paulo: Singular, 2006.

GOMES FILHO, Antonio Magalhães. Direito à prova no processo penal. São Paulo: Ed. Revista dos Tribunais, 1997.

. Notas sobre a terminologia da prova (reflexos no processo penal brasileiro). In: YARSHELL, Flávio Luiz; MORAES, Maurício Zanoide de (Org). Estudos em homenagem à Professora Ada Pellegrini Grinover. São Paulo: DPI, 2005. p. 303-318.

GRECO FILHO, Vicente. Direito processual civil brasileiro. 12. ed. São Paulo: Saraiva, 1997. v. 2.

Manual de processo penal. 7. ed. São Paulo: Saraiva, 2009.

GRINBERG, Mauro; MOTTA, Ricardo Casanova; FERNANDES, Luís Henrique. O cartel e sua prova. Revista do IBRAC - Direito da Concorrência, Consumo e Comércio Internacional, v. 25, p. 125-135, jan. 2014.

GUERREO RODRÍGUEZ, Omar; RAMIREZ CASAZZA, Alan. Mexican Competition Law aligned incentives for effective cartel enforcement. 2012. Disponível em: $<$ https://www.competitionpolicyinternational.com/mexican-competition-law-alignedincentives-for-effective-cartel-enforcement>. Acesso em: $01 \mathrm{dez} .2014$.

HOVENKAMP, Herbert. Federal ajtitrust policy: the law of competition and its practice. 3. ed. St. Paul: Thomson West, 2005.

INTERNATIONAL COMPETITION NETWORK - ICN. Agency effectiveness Competition Agency Practice Manual. March 2010. Disponível em: $<$ http://www.internationalcompetitionnetwork.org/uploads/library/doc744.pdf >. Acesso em: 01 nov. 2014.

KOVACIC, William E. The institutions of antitrust law: how structure shapes substance. Michigan Law Review, v. 110, 1019, 1042-1043, 2012.

; HYMAN, David A. Competition agency design: what's on the menu? 2012. Working Paper. Disponível em: 〈http://ssrn.com/abstract=2179279>. Acesso em: 29 out. 2014. 
LASSERRE, Bruno. The European competition system in context: matching old constitutional principles and new policy changes. In: EHLERMANN, Claus-Dieter; MARQUIS, Mel (Dirs).. European competition law 2009: the evaluation of evidence and its judicial review in competition cases. Oxford e Portland: Hart Publishing, 2011. p. 61-78.

LOPES, João Batista. A prova no direito processual civil. 3. ed., São Paulo: Ed. Revista dos Tribunais, 2006.

LOPES JÚNIOR, Aury; GLOECKNER, Ricardo Jacobsen. Investigação preliminar no processo penal. 5. ed. São Paulo: Saraiva, 2013.

LOWE, Philip. Taking sound decisions on the basis of available evidence. In: EHLERMANN, Claus-Dieter; MARQUIS, Mel (Eds.). European competition law 2009: the evaluation of evidence and its judicial review in competition cases. Oxford e Portland: Hart Publishing, 2011. p. 157-174.

LOWE, Philip. The Design of Competition Policy Institutions for the 21st Century-The Experience of the European Commission and DG Competition. 2008. Disponível em: $<$ https://www.competitionpolicyinternational.com/the-design-of-competition-policyinstitutions-for-the-21st-centurythe-experience-of-the-european-commission-and-dgcompetition/>. Acesso em: $01 \mathrm{dez} .2014$.

LUGARD, Paul. Procedural fairness and transparency in antitrust cases: work in progress. 16.06.2014. Disponível em: <https://www.competitionpolicyinternational.com/procedural-fairness-and-transparencyin-antitrust-cases-work-in-progress/>. Acesso em: 01 dez. 2014.

MANTZARI, Despoina; KORAH, Valentine. It takes one to tango: the single U.K. competition and markets authority. 14.05.2012. Disponível em: $<$ https://www.competitionpolicyinternational.com/it-takes-one-to-tango-the-single-u-kcompetition-and-markets-authority/>. Acesso em: $01 \mathrm{dez} .2014$.

MARANHÃO, Juliano Souza de Albuquerque; AZEVEDO, Paulo Furquim de; FERRAZ JUNIOR, Tércio Sampaio. Direito regulatório e concorrencial no Poder Judiciário. São Paulo: Singular, 2014.

MARQUIS, Mel. Rules that govern rules: evidence, proof and judicial control in competition cases. In: EHLERMANN, Claus-Dieter; MARQUIS, Mel. European competition law 2009: the evaluation of evidence and its judicial review in competition cases. Oxford e Portland: Hart Publishing, 2011. p. xv-xcii. 
MARTINEZ, Ana Paula. Histórico e desafios do controle de concentrações econômicas no Brasil. In: CAMPILONGO, Celso Fernandes; GILBERTO, André Marques; VILELA, Juliana Girardelli (Orgs.). Concentração de empresas no direito antitruste brasileiro. São Paulo: Singular, 2011. p. 21-59.

- Repressão a cartéis: interface entre direito administrativo e direito penal. São Paulo: Singular, 2013.

MEDAUAR, Odete. Direito administrativo moderno. 9. ed. São Paulo: Ed. Revista dos Tribunais, 2005.

. Poder de polícia. Revista de Direito Administrativo, Rio de Janeiro, v. 199, p. 8996, jan./mar. 1995.

A processualidade no direito administrativo. 2. ed. São Paulo: Ed. Revista dos Tribunais, 2008.

MEIKLEJOHN, Roderick. The effectiveness of competition authorities: four questions. 11.09.2014. Disponível em: <https://www.competitionpolicyinternational.com/theeffectiveness-of-competition-authorities-four-questions/>. Acesso em: $01 \mathrm{dez} .2014$.

MELLO, Maria Tereza Leopardi; POSSAS, Mario Luiz. Direito e economia na análise de condutas anticompetitivas. In: POSSAS, Mario Luiz (Coord.) Ensaios sobre economia e direito da concorrência. São Paulo: Singular, 2002.

MELlO, Rafael Munhoz de. Princípios constitucionais do direito administrativo sancionador: as sanções à luz da Constituição Federal de 1988. São Paulo: Malheiros Ed., 2007.

MÖLLMANN, Martin. Due process in antitrust proceedings before the European Commission: fundamental rights are not enough. 16.06.2014. Disponível em: $<$ https://www.competitionpolicyinternational.com/due-process-in-antitrust-proceedingsbefore-the-european-commission-fundamental-rights-are-not-enough/>. Acesso em: 01 dez. 2014.

MOREIRA, Egon Bockmann. Processo administrativo: princípios constitucionais e a Lei 9.784/1999. 3. ed. São Paulo: Malheiros Ed., 2007.

NOMAN, Gustavo Lage. Das provas em processo concorrencial. 2010. Dissertação (Mestrado) - Faculdade de Direito da Pontifícia Universidade Católica de São Paulo, São Paulo, 2010.

NUCCI, Guilherme de Souza. Provas no processo penal. 2. ed., São Paulo: Ed. Revista dos Tribunais, 2011. 
ORGANIZAÇÃO PARA A COOPERAÇÃO E DESENVOLVIMENTO ECONÔMICO OCDE. Hard Core Cartels: third report on the implementation of the 1998 Council Recommendation. 2005.2 Disponível em: <http://www.oecd.org/daf/competition/cartels/35863307.pdf>. Acesso em: 21 out. 2014.

. Recommendation of the OECD Council Concerning Effective Action Against Hard Core Cartels. 1998. Disponível em: <http://www.oecd.org/daf/competition/2350130.pdf>. Acesso em: 21 out. 2014.

Roundtable on procedural fairness: transparency issues in civil and administrative proceedings - European Union. 16 Feb. 2010. Disponível em: $<$ http://ec.europa.eu/competition/international/multilateral/2010_fairness_feb.pdf >. Acesso em: 01 set. 2014.

ORTIZ BLANCO, Luis. Standards of proof and personal conviction in EU antitrust and merger control procedures. In: EHLERMANN, Claus-Dieter; MARQUIS, Mel (Eds.). European competition law 2009: the evaluation of evidence and its judicial review in competition cases. Oxford e Portland: Hart Publishing, 2011. p. 175-190.

OSÓRIO, Fábio Medina. Direito administrativo sancionador. 4. ed. São Paulo: Ed. Revista dos Tribunais, 2011.

PAIVA, Tomás Filipe Schoeller Borges Ribeiro. O "e" escarlate da nova lei de defesa da concorrência: notas interpretativas sobre o art. 36 da Lei 12.529/2011. Revista do IBRACDireito da Concorrência, Consumo e Comércio Internacional, São Paulo, v. 24, p. 171187, jul. 2013.

PALMA, Juliana Bonacorsi de. Acordos substitutivos dão mais eficácia ao direito da concorrência? In: SUNDFELD, Carlos Ari; ROSILHO, André. Direito da regulação e políticas públicas. São Paulo: Malheiros Ed, 2014. p. 186-239.

PEREIRA NETO, Caio Mario da Silva; LANCIERI, Filippo Maria; ADAMI, Mateus Piva. O diálogo institucional das agências reguladoras. In: SUNDFELD, Carlos Ari; ROSILHO, André (Coords.). Direito da regulação e políticas públicas. São Paulo: Malheiros Ed., 2014. p. 140-185.

PITOMBO, Sérgio Marcos de Moraes. Procedimento administrativo criminal, realizado pelo Ministério Público. Revista Criminal, ano 5, v. 15, p. 155-157, set./dez. 2011. Texto elaborado em 2002.

PRAXEDES, Renata Rodrigues. Valoração de prova na condenação de cartéis - o mercado de revenda de combustíveis. Revista do IBRAC - Direito da Concorrência, Consumo e Comércio Internacional, São Paulo, v. 22, p. 341-354, jul./dez. 2012. 
RATLIFF, John. Judicial review in EC competition cases before the European courts: avoiding double renvoi. In: EHLERMANN, Claus-Dieter; MARQUIS, Mel (Dirs.). European competition law 2009: the evaluation of evidence and its judicial review in competition cases. Oxford e Portland: Hart Publishing, 2011. p. 453-472.

RIBAS, Guilherme Favaro Corvo. Contratualização administrativa no direito concorrencial. In: ZANOTTA, Pedro; BRANCHER, Paulo (Orgs.). Desafios atuais da regulação econômica e concorrência. São Paulo: Atlas, 2010. p. 87-104.

. Poder de polícia do Conselho Administrativo de Defesa Econômica (CADE). In: MEDAUAR, Odete; SCHIRATO, Vitor Rhein (Coords.). Poder de polícia na atualidade. Belo Horizonte: Fórum, 2014. p. 257-267.

. O princípio da presunção de inocência no processo administrativo sancionador. In: MEDAUAR, Odete; SCHIRATO, Vitor Rhein (Orgs.). Atuais rumos do processo administrativo. São Paulo: Ed. Revista dos Tribunais, 2010. p. 175-191.

RODAS, João Grandino; OLIVEIRA, Gesner. Direito e economia da concorrência. Rio de Janeiro: Renovar, 2004.

ROSA, José Del Chiaro Ferreira da; DANIEL, Juliana Maia; PEREIRA JÚNIOR, Ademir Antonio. A prova emprestada nos processos administrativos para investigação da prática de cartel. Revista do IBRAC - Direito da Concorrência, Consumo e Comércio Internacional, São Paulo, v. 17, p. 275-292, jan./jun. 2010.

SALOMÃO FILHO, Calixto. Direito concorrencial: as condutas. São Paulo: Malheiros Ed., 2003.

SANTOS, Moacyr Amaral. Prova judiciária no cível e comercial. 4. ed. São Paulo: Max Limonad, 1970. v. 1.

SCHIRATO, Vitor Rhein. O processo administrativo como instrumento do Estado de Direito e da Democracia. In: MEDAUAR, Odete; SCHIRATO, Vitor R. (Orgs.). Atuais rumos do processo administrativo. São Paulo: Ed. Revista dos Tribunais, 2010. p. 9-52.

SCHUARTZ, Luis Fernando. Ilícito antitruste e acordos entre concorrentes. In: POSSAS, Mario Luiz (Coord.) Ensaios sobre economia e direito da concorrência. São Paulo: Singular, 2002. p. 97-134.

SCORDAMAGLIA-TOUSIS, Andreas. EU cartel enforcement. Reconciling effective public enforcement with fundamental rights. Wolters Kluwer, 2013. 
SHROFF, Cyril; UBEROI, Nisha Kaur. Competition Commission of India: institutional design and decision making. 11.09.2014. Disponível em: $<$ https://www.competitionpolicyinternational.com/competition-commission-of-indiainstitutional-design-and-decision-making/>. Acesso em: 01 dez. 2014.

SILVEIRA, Paulo Burnier; OLIVEIRA, Giovanna Bakaj Rezende. A segunda década da Rede Internacional da Concorrência: os desafios da promoção da convergência na diversidade. Revista de Defesa da Concorrência, n. 1, p. 4-15, maio 2013.

SOCIEDADE BRASILEIRA DE DIREITO PÚBLICO - SBDP. Revisão judicial das decisões do Conselho Administrativo de Defesa Econômica (CADE): pesquisa empírica e aplicada sobre os casos julgados pelos Tribunais Regionais Federais (TRFs), Superior Tribunal de Justiça (STJ) e Supremo Tribunal Federal (STF). Belo Horizonte: Fórum, 2011.

SUNDFELD, Carlos Ari. Empresa estatal pode exercer o poder de polícia. BDA - Boletim de Direito Administrativo, Rio de Janeiro, p. 98-103, fev. 1993.

Poder instrutório do relator no processo administrativo. In: Direito administrativo econômico. São Paulo: Ed. Revista dos Tribunais, 2013. p. 561-583. (Coleção pareceres, v. 1).

; ROSILHO, André. Direito e políticas públicas: dois mundos? In: SUNDFELD, Carlos Ari; ROSILHO, André (Coords.). Direito da regulação e políticas públicas. São Paulo: Malheiros Ed., 2014. p. 45-79.

TAKIGAWA, Toshiaki. Balancing fairness and efficiency in the globalized competition law enforcement: insights from JFTC experiences. 16.06.2014 Disponível em: $<$ https://www.competitionpolicyinternational.com/balancing-fairness-and-efficiency-inthe-globalized-competition-law-enforcement-insights-from-jftc-experiences>. Acesso em: 01 dez. 2014.

TALAMINI, Eduardo. Prova emprestada no processo civil e penal. Revista de Processo, São Paulo, n. 91, p. 92-114, jul./set. 1998.

TANGERINO, Davi de Paiva Costa; ABRAMOVAY, Pedro Vieira et al. Crime de cartel e reparação de danos no poder judiciário brasileiro. Brasília: Ministério da Justiça, 2012. (Série Pensando o Direito, v. 47).

TARUFFO, Michele. La prova dei fatti giuridici. Milano: Giuffrè, 1992.

VARNEY, Christine A. Discurso proferido na Conferência de Concorrência da International Bar Association, Itália, 12.09.2009. Disponível em: <https://www.competitionpolicyinternational.com/remarks-by-assistant-attorney-generalchristine-a-varney-at-the-competition-conference>. Acesso em: 09 set. 2014. 
VENIT, James. Human all too human: the gathering and assessment of evidence and the appropriate standard of proof and judicial review in Commission enforcement proceedings applying Articles 81 and 82. In: EHLERMANN, Claus-Dieter; MARQUIS, Mel (Eds.). European competition law 2009: the evaluation of evidence and its judicial review in competition cases. Oxford e Portland: Hart Publishing, 2011. p. 191-254.

VIEIRA, Renato Stanziola. Paridade de armas no processo penal. Brasília: Gazeta Jurídica, 2014.

WHISH, Richard. Competition law. 6. ed. New York: Oxford University Press, 2009.

WILS, Wouter P. J. The combination of the investigative and prosecutorial function with the adjudicative function in EC antitrust enforcement: a legal and economic analysi. World Competition, v. 27, n. 2, 2004. Disponível em: 〈http://ssrn.com/abstract=1319251〉. Acesso em: 18 mar. 2014.

WONG, Stanley. Thinking about procedural fairness of competition law enforcement across jurisdictions: a suggested principled approach. Disponível em: <https://www.competitionpolicyinternational.com/assets/Uploads/ICNApril142.pdf>. Acesso em: 12 set. 2014. 